\title{
Investigation of the effect of tens treatment on cardiac electrical activity using proarrhythmogenic markers
}

\author{
달ol Öten ${ }^{1}$, @Mustafa Çapraz ${ }^{2}$ \\ ${ }^{1}$ Amasya University, Faculty of Medicine, Department of Physical Medicine and Rehabilitation, Amasya, Turkey \\ ${ }^{2}$ Amasya University, Faculty of Medicine, Department of Internal Medicine, Amasya, Turkey
}

Cite this article as: Öten E, Çapraz M. Investigation of the effect of tens treatment on cardiac electrical activity using proarrhythmogenic markers. J Health Sci Med 2021; 4(3): 349-352.

\begin{abstract}
Aim: It was aimed to investigate the effect of transcutaneous electrical nerve stimulation (TENS) treatment, which is widely used for pain, on cardiac electrical activity by using new proarrhythmogenic markers that give an idea on cardiac arrhythmia.

Material and Method: Forty patients (21 females, 19 males, mean age 56.60 10.38 ) who applied to our outpatient clinic with the complaint of pain in the left shoulder or limitation of motion were included in our study. A fifteen-session physical therapy program was applied to the patients. Twelve-lead electrocardiography (ECG) was performed before treatment, at the end of the first day of treatment, and after treatment; and heart rate, QT interval (cQT) corrected according to Bazett's formula, $\mathrm{Tp}-\mathrm{e} / \mathrm{QT}$ and electrophysiological balance index (iCEB) ratio were measured. The relationship of the measurements before treatment-first day after treatment, before treatment-fifteenth day after treatment and first day after treatment-fifteenth day after treatment was evaluated by Paired-Samples T test analysis.

Results: In our study, when heart rate, $\mathrm{CQT}, \mathrm{Tp}-\mathrm{e} / \mathrm{QT}$ and iCEB values were statistically analyzed, no significant difference was observed between measurements, since $\mathrm{p}>0.05$.

Conclusion: In our study, when the heart rate, new proarrhythmogenic markers cQT, Tp-e/QT and iCEB values were examined in patients who received physical therapy to the left shoulder region, it was seen that TENS treatment did not have a significant effect on cardiac rhythm.
\end{abstract}

Keywords: TENS, ECG, rhythm, cQT, Tp-e/QT ratio and iCEB

\section{INTRODUCTION}

Transcutaneous electrical nerve stimulation (TENS) is a widely used noninvasive, non-pharmacological treatment for pain (1). TENS, a clinical application of the gate control theory defined by Melzack and Wall in 1965 , is a low-voltage electrical current in which largediameter sensory fibers are stimulated by electrons on the skin in order to reduce nociceptive input $(2,3)$. TENS has been used to treat a wide variety of acute and chronic painful conditions since the 1970s. TENS is a relatively safe, noninvasive and easy to use treatment option (4). TENS has no serious side effects and contraindications, except for skin irritation, pacemaker, bleeding disorders, pregnancy, and epilepsy (5).

The standard superficial electrocardiogram (ECG) is a simple and widely used diagnostic tool that shows cardiac electrical activity. The prolongation of the QT interval, a marker for electrical instability, is the best known ECG sign for arrhythmia (6). In addition, in the twelve-lead
ECG, Tp-e, defined as the distance between the peak and the end of the T wave, and $\mathrm{iCEB}$, formulated as the Tp-e/QT ratio and the QT interval/QRS duration, are new proarrhythmogenic markers that give an idea about cardiac arrhythmia (7-10).

In this study, it is aimed to investigate whether the treatment has a negative effect in terms of cardiac arrhythmia by evaluating heart rate, cQT, Tp-e/QT and iCEB measurements on ECG in patients who received conventional TENS treatment in the left shoulder area, which is the body part closest to the anterior chest wall.

\section{MATERIAL AND METHOD}

A total of 40 patients, 21 women and 19 men, who applied to the Physical Medicine and Rehabilitation outpatient clinic of Amasya University Sabuncuoğlu Şerefeddin Training and Research Hospital, between October 2019 and February 2020, between the ages of 18 and 80 with 
complaints of left shoulder pain or limitation of motion, were included in the study. Ethics committee approval of the study was obtained from the Ethics Committee of Amasya University (Date: 03.09.2020, Decision No: 105). For the patients included in our study, infrared (20 $\mathrm{min})$, TENS (20 min), ultrasound (5 min) and 15 min exercise program were planned as fifteen sessions. Physical therapy sessions were administered daily, Monday through Friday, for 3 weeks. Patients with heart rhythm disorders, pacemaker, pregnancy and neuroendocrine diseases such as diabetes, and hypo/ hyperthyroidism were not included in our study. Conventional TENS was applied with four standard electrodes placed in the anterior and upper regions of the left shoulder with an amplitude width of $0.2 \mathrm{~ms}$ and a frequency of $80 \mathrm{~Hz}$. The intensity of the stimulation was increased until a perceptible tingling sensation was experienced by the patient. ECGs were recorded with a standard 12-lead ECG at $25 \mathrm{~mm} / \mathrm{s}$ paper speed and $10 \mathrm{~mm} / \mathrm{mV}$ amplification. ECG measurements were made three times in total, before the treatment, after the first session and after the fifteenth session. ECGs were evaluated by a single physician who had no knowledge of clinical findings.

In the ECG, the QT interval was accepted as the time elapsed from the beginning of the QRS complex to the end of the T wave. Derivation II and V5 were used to measure the QT interval. Then, with Bazett's formula, the corrected QT interval (cQT) was calculated: $\mathrm{cQT}=\mathrm{QT} \sqrt{ }$ (R-R interval) (11). In the chest leads, the Tp-e interval was determined by measuring the time between the peak of the $\mathrm{T}$ wave and the end of the $\mathrm{T}$ wave $(12,13)$. The Tp-e/QT ratio was calculated as the ratio of Tp-e time in lead V5 to the QT interval in the same lead, and the cardiac electrophysiological balance index $(\mathrm{iCEB}=\mathrm{QT} / \mathrm{QRS})$ was calculated by evaluating derivation II or V5 (14).

\section{Statistical analysis}

SSPS $^{\circledast}$ version 21.0 statistical package program (SPSS Inc., Chicago, IL, United States) was used for statistical analysis. Continuous variables were expressed as mean \pm standard deviation. Relationships between heart rate, cQT, Tp-e/ QT and iCEB measurements before, on the first day after treatment and on the fifteenth day after treatment were calculated using the Paired-Samples T test. $\mathrm{P}<0.05$ values were considered statistically significant.

\section{RESULTS}

The average age of the study population is $56.60 \pm 10.38$ and it consists of 19 male (47.5\%) and 21 female (52.5\%) patients. The demographic characteristics of the patients are shown in Table 1.

\begin{tabular}{|lcc|}
\hline \multicolumn{3}{|c|}{ Table 1. Demographic characteristics 40} \\
\hline Age & 56.60 & \pm 10.38 \\
Gender & & \\
$\quad$ Male & 19 & $\% 47.5$ \\
Female & 21 & $\% 52.5$ \\
BMI & 31.0225 & \pm 5.38819 \\
\hline
\end{tabular}

Average and standard deviations of the measurements of heart rate, cQT, Tp-e/QT and iCEB values before treatment, on the first day after treatment and on the fifteenth day after treatment in ECG are shown in Table 2. The values of the measurements before the treatment and after the treatment on the first day, before the treatment and on the fifteenth day after the treatment, on the first day after the treatment and on the fifteenth day after treatment were compared with the Paired-Samples $\mathrm{T}$ test and it is shown that no significant difference was observed between them, in Table 3 .

\begin{tabular}{|lccc|}
\hline Table 2. Heart rate, cQT, Tp-e/QT and iCEB average values \\
\hline & $\begin{array}{c}\text { Before } \\
\text { treatment }\end{array}$ & $\begin{array}{c}\text { First day after } \\
\text { treatment }\end{array}$ & $\begin{array}{c}\text { Fifteenth } \\
\text { day after } \\
\text { treatment }\end{array}$ \\
\hline Heart rate & $71.95 \pm 8.21$ & $70.80 \pm 10.41$ & $70.72 \pm 10.83$ \\
cQT (ms) & $433.25 \pm 40.84$ & $433.30 \pm 32.52$ & $424.70 \pm 33.03$ \\
Tp-e/QT ratio & $0.126 \pm 0.04$ & $0.127 \pm 0.040$ & $0.131 \pm 0.030$ \\
iCEB (QT/QRS) & $4.52 \pm 0.10$ & $4.58 \pm 0.11$ & $4.64 \pm 0.09$ \\
\hline
\end{tabular}

\begin{tabular}{|lcccc|}
\hline $\begin{array}{l}\text { Table 3. P values of heart rate, cQT, Tp-e/QT and iCEB } \\
\text { measurements }\end{array}$ & $\begin{array}{c}\text { Heart } \\
\text { Rate }\end{array}$ & $\begin{array}{c}\text { cQT } \\
(\mathbf{m s})\end{array}$ & $\begin{array}{c}\text { Tp-e/ } \\
\text { QT } \\
\text { Ratio }\end{array}$ & $\begin{array}{c}\text { iCEB } \\
\text { (QT/ } \\
\text { QRS) }\end{array}$ \\
\hline $\begin{array}{l}\text { Before treatment-First day } \\
\text { after treatment }\end{array}$ & .289 & .990 & .728 & .613 \\
$\begin{array}{l}\text { Before treatment-Fifteenth } \\
\text { day after treatment }\end{array}$ & .290 & .253 & .230 & .152 \\
$\begin{array}{l}\text { First day after treatment- } \\
\text { Fifteenth day after treatment }\end{array}$ & .941 & .095 & .302 & .587 \\
\hline
\end{tabular}

\section{DISCUSSION}

In this study, the effects of TENS on cardiac rhythm were evaluated by measuring heart rate and proarrhythmogenic markers in patients without cardiac disease who presented to our outpatient clinic with pain or limitation in the left shoulder. TENS treatment applied to the left shoulder, the region closest to the heart, did not have a significant effect on ECG parameters.

TENS is a simple, reliable and reusable treatment method applied in daily clinical practice in the treatment of many acute or chronic painful conditions (15). Since the 19th century, although TENS has been reported to have analgesic and anesthetic effects and has been used 
for a long time by some clinicians, the mechanisms that reduce pain or provide analgesia have only recently been explained. Various theories explaining peripheral and central mechanisms support the use of TENS to provide analgesic effect (16-19). While adrenergic receptors are part of the peripheral mechanism, endogenous opioid release and gate control are part of the central mechanism. In clinical practice, TENS types are available that are obtained by modulating the stimulation frequency, amplitude and wavelengths. We included patients who received high frequency $(50-100 \mathrm{~Hz})$, low-intensity conventional TENS therapy, which is more commonly used in physical therapy protocols.

The autonomic nervous system plays an important role in the nervous control of the cardiovascular system. When previous studies were reviewed, regarding the effects of TENS on the sympathetic and parasympathetic nervous system, Wong et al. reported an increase in sympathetic tonus (20). However, Sanderson et al. showed a decrease in sympathetic activity after TENS use (21), and Buonocore et al. showed that there was no change in autonomic nerve control of the heart (22). This shows that a definite judgment cannot be made about the effect of TENS on heart rate changes through sympathetic and parasympathetic modulation (23).

In addition, another possible TENS application area that can affect heart rhythm is the back area. This area is the paravetebral ganglion area where the sympathetic nerve innervation of the heart, adrenal gland and vessels is located (24). In the study of Cinara et al. (23), they hypothesized that TENS application to this area may cause sympathetic modulation and a decrease in circulating catecholamine levels.

There are a limited number of studies in the literature examining the effects of TENS treatment on heart rhythm. Ağırman and Aydın stated that the effects of TENS treatment on cardiac rhythm were not statistically significant in their study on 41 patients (26 women, 15 men), which included heart rate and QTc measurements (25). However, except for heart rate and QTC values, Tp-e/ QT and iCEB ratios are used as new proarrhythmogenic markers to determine cardiac arrhythmia (10).

The main limitation of this study is that it was performed on healthy individuals who do not have any cardiac problems and who do not have any additional disease that may disrupt the heart rhythm. Also, manual evaluation of ECG parameters can be considered as another limitation. However, these shortcomings can be overcome with further studies. Not applying TENS to other areas close to the heart can be considered as an additional limitation in evaluating its effect on the cardiac rhythm.

\section{CONCLUSION}

In conclusion, by evaluating heart rate, $c \mathrm{QT}, \mathrm{Tp}-\mathrm{e} / \mathrm{QT}$ and $\mathrm{iCEB}$ measurements, which can be easily obtained from ECG parameters, it was observed that TENS treatment applied to the left shoulder area, which is the closest to the heart, did not have negative effects on heart rhythm in patients without heart disease. Lastly, further studies are needed to examine the effects of TENS amplitude and frequency changes on heart rhythm and pro-arrhythmogenic markers.

\section{ETHICAL DECLARATIONS}

Ethics Committee Approval: The study was carried out with the permission of Research Ethics Committee of Amasya University (Date: 03.09.2020, Decision No: 105).

Informed Consent: Because the study was designed retrospectively, no written informed consent form was obtained from patients.

Referee Evaluation Process: Externally peer-reviewed.

Conflict of Interest Statement: The authors have no conflicts of interest to declare.

Financial Disclosure: The authors declared that this study had received no financial support.

Author Contributions: All of the authors declare that they have all participated in the design, execution, and analysis of the paper and approved the final version.

\section{REFERENCES}

1. DeSantana JM, Walsh DM, Vance C, Rakel BA, Sluka KA. Effectiveness of transcutaneous electrical nerve stimulation for treatment of hyperalgesia and pain. Curr Rheumatol Rep 2008; 10: 492 .

2. Melzack R, Wall PD. Pain mechanisms: a new theory. Science 1965; 150: 971-9.

3. Chabal C, Fishbain DA, Weaver M, Heine LW. Long-term transcutaneous electrical nerve stimulation (TENS) use: impact on medication utilization and physical therapy costs. Clin J Pain 1998; 14: 66-73.

4. Khadilkar A, Odebiyi DO, Brosseau L, Wells GA. Transcutaneous electrical nerve stimulation (TENS) versus placebo for chronic low-back pain. Cochrane Database Syst Rev 2008: 4.

5. Jones I, Johnson MI. Transcutaneous electrical nerve stimulation. Continuing Education in Anaesthesia, Crit Care Pain 2009; 9: 130-5.

6. Straus SM, Kors JA, De Bruin ML, et al. Prolonged QTc interval and risk of sudden cardiac death in a population of older adults. J Am College Cardiol 2006; 47: 362-7.

7. Yontar OC, Karaagac K, Tenekecioglu E, Tutuncu A, Demir M, Melek M. Assessment of ventricular repolarization inhomogeneity in patients with mitral valve prolapse: value of T wave peak to end interval. Int J Clin Experimental Med 2014; 7: 2173.

8. Meier P, Gloekler S, de Marchi SF, Zbinden R, Delacrétaz E, Seiler C. An indicator of sudden cardiac death during brief coronary occlusion: electrocardiogram QT time and the role of collaterals. Eur Heart J 2010; 31: 1197-204. 
9. Hetland M, Haugaa KH, Sarvari SI, Erikssen G, Kongsgaard E, Edvardsen T. A novel ECG index for prediction of ventricular arrhythmias in patients after myocardial infarction. Ann Noninvasive Electrocardiol 2014; 19: 330-7.

10. Lu HR, Yan G-X, Gallacher DJ. A new biomarker-index of cardiac electrophysiological balance (iCEB)-plays an important role in drug-induced cardiac arrhythmias: beyond QT-prolongation and torsades de pointes (TdPs). J Pharmacol Toxicol Methods 2013; 68: 250-9.

11. Funada A, Hayashi K, Ino H, et al. Assessment of QT intervals and prevalence of short QT syndrome in Japan. Clin Cardiol 2008; 31: 270-274.

12.Hevia JC, Antzelevitch C, Bárzaga FT, et al. Tpeak-Tend and Tpeak-Tend dispersion as risk factors for ventricular tachycardia/ ventricular fibrillation in patients with the Brugada syndrome. J Am College Cardiol 2006; 47: 1828-34.

13. Shimizu M, Ino H, Okeie K, et al. T-peak to T-end interval may be a better predictor of high-risk patients with hypertrophic cardiomyopathy associated with a cardiac troponin I mutation than QT dispersion. Clin Cardiol 2002; 25: 335-9.

14. Alsancak Y. Kardiyak elektrofizyolojik denge indeksi ve Tp-E/qt oranı ile koroner kollateral dolaşım arasındaki ilişki. Selçuk Tıp Derg 2019; 35: 169-75.

15. Johnson M, Ashton C, Thompson J. Long term use of transcutaneous electrical nerve stimulation at Newcastle Pain Relief Clinic. J Royal Society Med 1992; 85: 267.

16. Sluka KA, Walsh D. Transcutaneous electrical nerve stimulation: basic science mechanisms and clinical effectiveness. J Pain 2003; 4: 109-21.

17. Wall PD, Sweet WH. Temporary abolition of pain in man. Science 1967; 155: 108-9.

18. Johnson M. Transcutaneous electrical nerve stimulation: mechanisms, clinical application and evidence. Reviews in Pain 2007; 1: 7-11.

19. King EW, Audette K, Athman GA, Nguyen HOX, Sluka KA, Fairbanks CA. Transcutaneous electrical nerve stimulation activates peripherally located alpha- $2 \mathrm{~A}$ adrenergic receptors. Pain 2005; 115: 364-73.

20. Wong RA, Jette DU. Changes in sympathetic tone associated with different forms of transcutaneous electrical nerve stimulation in healthy subjects. Physical Therapy 1984; 64: 478-82.

21.Sanderson JE, Tomlinson B, Lau MS, et al. The effect of transcutaneous electrical nerve stimulation (TENS) on autonomic cardiovascular reflexes. Clin Auton Res 1995; 5: 81-4.

22. Buonocore M, Mortara A, La Rovere M, Casale R. Cardiovascular effects of TENS: heart rate variability and plethysmographic wave evaluation in a group of normal subjects. Funct Neurol 1992; 7: $391-4$.

23. Stein C, Dal Lago P, Ferreira JB, Casali KR, Plentz RDM. Transcutaneous electrical nerve stimulation at different frequencies on heart rate variability in healthy subjects. Auton Neurosci 2011; 165: 205-8

24.Janes RD, Brandys JC, Hopkins DA, Johnstone DE, Murphy DA, Armour JA. Anatomy of human extrinsic cardiac nerves and ganglia. Am J Cardiol 1986; 57: 299-309.

25. Ağirman M, Aydin Hi. Effect of the conventional transcutaneous electrical nerve stimulation on heart rhythm. J Physical Med Rehabil Sci/Fiziksel Tip ve Rehabil Bil Derg 2018; 21: 3. 